\title{
"Gente Quer luZiR": FiguraçÕes de "UM OUTRO-REAL, UM ULTRARREAL" NO ENFOQUE DA POBREZA ${ }^{1}$
}

\section{Ana Cristina de Rezende Chiara}

Gente quer luzir. Os mendigos drogados na calçada de NY sonham com pirulitos de metadona. A princesa inclina a cabeça e diz sim. $\mathrm{O}$ mendigo cineasta de Montreal explode a tela com imagens reais demais. A negra na esquina do Leblon para o tempo. As crianças se exercitam nos sinais, passarinhos sujos voando sobre o canal do Jardim de Alá. Aquele se lava no chafariz, na cena de Fellini, dois se amam sob pedaços de papelão. Dá pra ver o movimento. Adolescentes chupam chupetas nostálgicos. Outros preferem um cheirinho de cola. Muito bom. Pernas feridas. Bocas sem dente. Barrigões com bebês. Sexo a seco. Figuras recortadas da cidade. Brilham. Dançam. Ana Chiara (da série formas do irrespirável, inédito)

Perdeu o apetite, só tinha a grande fome. Clarice Lispector ( $A$ hora da estrela)

o Nikos, assim para te dar um exemplo, escreveu que quando ele encontrava um mendigo na rua, tinha vontade de dizer: me dá o seu tempo.

Hilda Hilst (Fluxo-floema)

"Rafael, de 25 anos, finge que é passarinho, mas passou a vida trancado. André, 20 anos, reza dias inteiros e grita o tempo todo. Leandro, 20 anos, engole esponjas de aço e cremes de cabelo. João Guilherme, 11 anos, come compulsivamente. Eles se automutilam e agridem até suas mães"*, diz a reportagem de 16 de julho de 2006, de $O$ Globo, que investiga as responsabilidades do Estado com relação ao tratamento de autistas pobres. Soraya Aggege, que

(AGGEGE, Soraya. "A vida segregada do brasileiro autista". In: O Globo, 16 jul. 2006.)

assina a matéria, continua: "as mães geralmente são o principal elo do autista com o mundo. Talvez por isso elas apanhem mais. Dentes e braços quebrados são consequências comuns nessas relações.

\footnotetext{
${ }^{1}$ A frase "gente quer luzir" cita o verso de Caetano Veloso na letra de Gente no LP/CD Bicho Philips/ Phonogram, de 1977.
} 
* (Santa Teresa de Jesus. $O$ livro da vida. São Paulo: Ed. Loyola, 1995: 129.)

* (cf. GAHNEBIN, Jeanne Marie. "O hino, a brisa e a tempestade: dos anjos em Walter Benjamin". In: $O$ Percevejo - Revista de teatro, crítica e estética. Ano 6, n. 6., 1988: 18-29.)
Para muitas delas, no entanto, eles são anjos que as fazem conviver em um outro mundo, onde simplesmente as regras são diferentes". Uma das mães diz sobre o filho: "O que ele me ensinou é como se ele vivesse em um país estrangeiro e me levasse para lá sempre. Mas ninguém mais consegue entrar”. Parece, então, que as mães atribuem ao isolamento dos meninos autistas um valor de excepcionalidade, como das experiências extáticas dos místicos. Repercute na memória a frase de Santa Teresa em seu Livro da vida:

Este sofrimento é semelhante às agonias da morte, mas traz em si tamanho contentamento que não tenho termos de comparação. [...] Digo não sabe porque a imaginação nada lhe apresenta. Acho até que as suas faculdades não agem em grande parte do tempo em que ela está assim. A dor as suspende, assim como o júbilo o faz na união e no arroubo.*

A comparação com anjos remete também a Walter Benjamin e a alguns de seus anjos incompletos, figuras efêmeras e incapacitadas, anjos doloridos, mas cintilantes.* Segundo Gagnebin, para o filósofo alemão, os anjos são figuras intersticiais, figuras que se situam no limiar de uma aparição e de um desaparecimento, figuras fugazes e iluminadoras. Embora de lume fraco, esses anjos autistas, em suas intensas relações com suas mães, funcionam como uma interdição à leitura fluida da reportagem. Eles demandam mais do que uma simples piedade, eles obrigam a repensar as relações entre a privação e o excesso em que mergulha até a raiz nossa sociedade.

O efeito perturbador da reportagem decorre da desordem provocada na expectativa de leitores de jornal. Onde esperam o factual, deparam com imagens verbais desconcertantes construídas por uma espécie de aberração entre o que se diz e o modo como se diz. A vida miserável de pessoas entregues a uma disfunção mental e sem condiçôes de tratamento adquire um inesperado contorno. Algo se intromete entre o leitor e as páginas do jornal, uma vacilação entre a razão e a perplexidade. Um espaço vago a ser preenchido por uma relação desconhecida entre o olho que vê, lê, e aquilo que é visto, lido. $\mathrm{O}$ que explicaria esse enfoque que torna o real algo além do que pode abarcar a compreensão imediata dos fatos?

Entre a imagem do passarinho, a reza misturada a gritos, a dieta sensual e a dor das mães, imiscui-se uma compreensão inesperada de que há outros estados da consciência e dos corpos que, por mais irrespiráveis que sejam, nos projetam num outro-real: um 
ultrarreal. A devoção das mães pelos filhos-anjos é quase religiosa, e o amor por esses "meninos do porão", como os chama um dos psiquiatras entrevistados, sustentam-nas em seus cotidianos massacrantes. Buscariam talvez compensações para suportar o sofrimento, mas não gostaria de pensar por meio de psicologismos redutores. Quero entender a partir dessas imagens dos meninos autistas como e por que certas imagens verbais e visuais da miséria, do isolamento, da pobreza provocam um tipo de choque diferente do sentimento de compaixão passiva que as imagens costumeiras da pobreza/privação costumam provocar. Considero aqui imagens da pobreza, da miséria, da privação, imagens de estados extremos, próximos do êxtase, contrapondo-se aos clichês sobre a miséria.

É por demais conhecida a aterradora experiência de Georges Bataille diante do suplício de um rapaz chinês. Bataille recebeu um negativo de uma das fotos do suplício à qual frequentemente voltava e, mais tarde, obteve ainda outras imagens da tortura: "Estou obcecado pela imagem do carrasco chinês da minha fotografia em seu trabalho de cortar a perna da vítima na altura do joelho"*;2 em outro comentário, Bataille se refere à vítima:

O jovem e sedutor chinês [...] entregue ao trabalho do carrasco, eu o amava: [...] eu o amava de um modo no qual o instinto sádico não tomava parte: ele me comunicava sua dor, ou antes, o excesso de sua dor, e era justamente isso que eu buscava, não para me deliciar, mas para arruinar em mim aquilo que se opõe à ruína.*

Estimulado por essa vivência, Bataille escreverá o livro $A$ experiência interior, o primeiro que assina com o nome verdadeiro, e, sob o influxo das intrincadas reaçóes às fotos, estuda a possibilidade de um descarte de saber prévio e o mergulho no em si mesmo

\footnotetext{
${ }^{2}$ No artigo citado, Augusto Contador Borges escreve: "Em 1905, na China imperial, um jovem chamado Fou Tchou Li foi considerado culpado pelo assassinato de um príncipe, Ao Han Ouan, e submetido ao terrível "suplício dos Cem pedaços". Por clemência (sic) do imperador, a vítima não foi queimada como era previsto, mas esquartejada viva em cem pedaços. Dois franceses assistiram à execução e a documentaram. Um deles, Georges Dumas, publicou uma das fotos em 1923, em seu Tratado de psicologia. Dumas intrigara Bataille observando que, por piores que fossem o meticuloso trabalho do carrasco e as dores da vítima, o que se via em seus olhos revoltos era uma expressão de êxtase. É bem verdade que o supliciado encontrava-se sob efeito de injeçôes de ópio, não para mitigar seu sofrimento, como se poderia supor, mas para prolongá-lo ainda mais. O enigma estava criado."
}

* (BORGES, Augusto Contador. "Georges Bataille: imagens do êxtase". In: AguIha - Revista de cultura, 9. Fortaleza; São Paulo, fev. 2001.)

* (lbidem.) 
* (BATAILLE, Georges. A experiência interior. São Paulo: Ática, 1992: 183.)

* (lbidem: 39.)

* (LISPECTOR, Clarice. A hora da estrela. $9^{\text {aed. Rio }}$ de Janeiro: Nova Fronteira, 1984.) da experiência. Um movimento de ascese e de excesso, abrindo a percepção a estados não racionais, não preconcebidos por uma razão universal. A bela epígrafe nietzscheana "a noite também é um sol" confere a medida do que será revolucionado pelo pensamento do transe. Bataille provoca o pensamento até superar os limites do senso comum por meio de um processo de despossessão de si mesmo, dos saberes prévios, dos sentidos estabelecidos. Ele afirma:

Antes que a sorte me abandonasse, frequentemente achei de antemão o contra-senso como um pequeno fragmento de osso que se quebra atrozmente quando se saboreia uma garfada. Hoje nem garfada, nem sabor. Somente o contra-senso, verdade deserta, criando o deserto, entrevista, dilacerando através da folhagem das árvores sob o pálido azul do céu (que é ausência do homem e de qualquer sentido).*

Bataille convocará a força desse espaço desértico, onde o homem fará da fraqueza sua potência máxima. $\mathrm{O}$ homem do contrassenso reúne forças além de sua capacidade, reúne as forças do excesso de uma verdade grande demais para ser abarcada pelo pensamento. $\mathrm{O}$ suplício do chinês desencadeará uma reação análoga no observador:

[...] entro num beco sem saída. Aí toda possibilidade se esgota, o possível se esquiva e o impossível maltrata. Estar frente ao impossível - exorbitante, indubitável -, quando mais nada é possível, é, aos meus olhos, fazer uma experiência do divino; é o análogo de um suplício.*

Exorbito, portanto, da esfera conhecida da comiseração diante de imagens da pobreza e da privação, deixo que meu pensamento resvale como o das mães dos "meninos do porão" e me contamino com a miséria do outro, com a violência desse estado. Afundo na violência da miséria para compreendê-la, tornando o meu olhar tão miserável quanto aquilo que vê, para fazer com que a miséria seja um modo de conhecimento além da superfície das imagens e das palavras, algo que não me permita uma leitura fluida, um virar a página e esquecer. Proponho-me ainda experimentar a crueldade diante da dor dos outros. E que esta crueldade não se confunda com a simples maldade, mas que radicalmente me lance na crueza de um mundo a descobrir. Não foi esse o drama de linguagem encenado pelo narrador de $A$ hora da estrela?*

Para tanto é necessário vencer as barreiras dos preconceitos e prejulgamentos, renunciar ao anteparo ideológico da boa consciência e ultrapassar os limites da minha própria condição. O des- 
concertante em Macabéa de Clarice vem de seu extremo lirismo e delicadeza, que resiste a toda forma de brutalização. Ler Macabéa como nordestina subalterna, vitimada pela cidade, é dissolvê-la numa corrente que convoca no máximo os bons sentimentos humanistas e uma revolta fraca e momentânea. Talvez o que Susan Sontag chama de "compaixão e repugnância".*

David Lapoujade, ao estudar a relação de imbricação da religiosidade no mundo laico capitalista dos Estados Unidos, afirma: "[...] a caridade não supõe nenhuma simpatia por um sujeito, mas faz do outro o objeto de um cuidado. [...] ela se pretende medicinal ou curativa, pois só pode ter acesso a objetos que reclamam sua 'força de trabalho"”. * No entanto, Clarice, ao performatizar um narrador homem que não vai "lacrimejar piegas", encena o confronto agônico entre a repulsa e a simpatia, entre a crueldade e o amor diante da pobreza e do desamparo de Macabéa, sem se deixar capturar numa rede de bons sentimentos. Isto porque a nordestina deve permanecer como espanto para o pensamento. Ao se perguntar sobre Macabéa, o narrador não poderá fechá-la num conceito apenas: se a pobreza dela era "feia e promíscua", ${ }^{*}$ ela também "vivia de si mesma",* o que provoca inevitável desconcerto diante dessa alteridade irredutível, pois a nordestina tinha em si mesma uma certa "flor fresca".* A perplexidade do narrador diante da possibilidade de momentos gloriosos em meio a toda mesquinhez de um cotidiano apagado, sujo e pobre pode passar a ser também a perplexidade do leitor: "quem sabe achava que havia uma gloriazinha em viver?”* Clarice Lispector coloca o leitor não diante de uma pobreza que iguala a todos, mas o obriga a ver um outro naquele pobre, dá-lhe uma subjetividade como uma frágil flor, e esse olhar trocado volta-se para a própria fragilidade de quem lê, a fragilidade dos que possuem muito. Deixo por enquanto Macabéa ouvindo a rádio $\mathrm{MEC}$ e penso juntamente com um fotógrafo do pensamento do transe.

O fotógrafo Arthur Omar, na entrevista sobre a mostra de sua série Antropologia da Face Gloriosa, ${ }^{3}$ explica como se dá sua relação com a arte da fotografia. Para fotografar, Omar coloca-se em total disponibilidade diante do que conhecemos como o material

\footnotetext{
${ }^{3}$ Série de fotografias composta por fragmentos-flagrantes colhidos no carnaval de rua do Rio de Janeiro entre 1973 e 1996. Em: Catálogo da exposição realizada no MAM, Antropologia da Face Gloriosa, de 22 de janeiro a 25 de abril de 1999.
}

* (SONTAG, Susan. Diante da dor dos outros. São Paulo: Companhia das Letras, 2003: 17.)

* (LApOujADE, David. "Cinismo e piedade (Made in USA)". In: LINS, Daniel (org.). Nietzsche e Deleuze - Bárbaros, civilizados. São Paulo: Annablume, 2004: 77.)

* (LISPECTOR, Clarice. Op. cit.: 28.)

* (lbidem: 45.)

* (Ibidem: 47.)

* (Ibidem: 34.) 
* (OMAR, Arthur. Antropologia da face gloriosa. São Paulo: Cosac\&Naify, 1999: 41.)

* (lbidem: 41.)

* (Ibidem: 56.) a ser fotografado - no caso, os rostos de foliōes de rua do carnaval do Rio de Janeiro -, de modo a deixar que haja uma espécie de fusão, uma total sincronicidade com o fotografado de tal ordem que o olho que vê torne-se o que é visto, ou seja:

[...] através do ato fotográfico [...] onde o sujeito se insere num tipo de temporalidade diferente, muitos fotógrafos podem se tornar eles próprios gloriosos. Pois é somente tornando-se gloriosos, ou deixando-se atravessar pelo pequeno e fragmentário êxtase fotográfico, que eles podem entrar em fase de vibração sincronizada, com a glória que está atravessando o rosto do outro, ou melhor, o ser mesmo do seu objeto que ele não perceberia se não batesse no mesmo ritmo ou na mesma freqüência.*

Segundo Arthur Omar, desaparece nessa relação fusional o distanciamento que dá chance ao retrato e ao sociologismo, podese entrar num circuito imaterial de um ultrarreal, um outro-real, num circuito de forças gloriosas, de estados gozosos. Como poderemos ver numa de suas fotos - todas em grandes dimensóes -, o olho que vê é o olho visto e vê não com a pupila, mas com o branco dos olhos. Ao explicar uma foto da exposição intitulada Não te vejo com a pupila, mas com o branco dos olhos, o artista se aproxima do pensamento do transe de Georges Bataille na definição de uma experiência extática:

Em todas as representações plásticas de místicos em êxtase, os olhos sempre aparecem revirados para cima. Aparentemente porque estariam em contato com realidades superiores, acima deles. Mas ao posar para esta foto, descobri algo mais. Na verdade, o que o místico faz ao revirar os olhos para cima não é olhar para deus, mas vedar a sua pupila com as pálpebras, deixando aberto e solto no espaço o branco dos olhos, para que ele receba não apenas o que vem de cima, mas o que vem de todos os lados do cosmos.*

A soltura e opacidade do branco impedem a formação de um julgamento imediato, colocando a entrega ao outro no mesmo plano vertiginoso com que a câmera registra em segundos e secretamente, sem que o olho consiga perceber. As fotos de Artur Omar distorcem fisionomias, exageram, esticam ao máximo, são "defeituosas", granuladas, estouradas, são o antirretrato. São estados alterados. $\mathrm{O}$ espectador é tragado numa revolta do objeto contra o sujeito. Como diz o artista: "acho que o centro da imagem é um aparelho de sucção violenta, ao qual um dia enviaremos o olho em missão tripulada".* Se nessas fotos se suga o espectador para um centro, esse centro é um equivalente do redemoinho, força neutra 
de onde se pode sair apenas pelo deslocamento da perspectiva. As fotos de Arthur Omar contrariam o que Susan Sontag chama de "retórica da dor". A retórica da dor é invariável: reitera, simplifi$\mathrm{ca}$, agita, cria ilusão de consenso: " $\mathrm{E}$ as fotos das vítimas de guerra são, elas mesmas, uma modalidade de retórica. Elas reiteram. Simplificam. Agitam. Criam a ilusão de consenso".*

Num outro extremo da fotografia como arte, encontramos o trabalho de Sebastião Salgado. Trata-se, como todos reconhecem, de fotos de extrema beleza e impacto sobre o espectador. No entanto, poder-se-ia perguntar que tipo de recepção impactante é esse? Ao examinar o trabalho Exodos (2000), ${ }^{4}$ Karl Erik Schollhammer observa o efeito das fotos de Sebastiāo Salgado:

Não nos é permitido desviar o olhar! Somos fitados pelo olhar, às vezes hostil, do sujeito fotografado, de maneira que não nos é permitido baixar o olho. O espectador é, assim, exposto à catástrofe da história, encarnado no olhar hostil do "outro próximo", perdendo seu domínio representativo e virando, ele mesmo, o objeto passivo e culpado deste olhar. Nesse ponto, a relação paradoxal no trabalho de Salgado aparece como a dificuldade que distingue suas fotos da superexposição pornográfica das vítimas de catástrofes, promovida pela imprensa global, que apenas contribuem para a redundância, insensibilidade e banalidade acerca do sofrimento humano.*

O trabalho de Salgado, segundo observaçōes de Karl Erik Schollhammer, provoca no espectador um olhar "universal" sobre a pobreza. E, por mais contundentes, as cenas captadas acabam por reafirmar a retórica da dor, como se ouvíssemos ao fundo a música dos Titãs: "miséria é miséria em qualquer canto..." Nos retratos de Salgado, podemos contemplar as fotos das crianças refugiadas de várias nacionalidades diferentes que, vistas em conjunto, reforçam essa ideia de que os males se espalham pelo planeta afetando as pobres criancinhas, condenando-as ao mesmo tipo de exílio na pobreza. Talvez, por sua extrema qualidade estética, possam até ser incluídos no que Ivana Bentes classifica, quanto a um certo cinema dos anos 1990, como "cosmética da fome": "filmes em que a linguagem e a fotografia clássicas transformam o sertão num jardim

\footnotetext{
${ }^{4}$ Exodos (2000) - O projeto de Êxodos se baseia numa seleção de mais de 80.000 fotos tiradas durante a última década e representa um resumo de sua carreira de fotógrafo documental. O livro tem quatro partes separadas: Migração e refugiados; a Tragédia Africana; América Latina: o êxodo rural e a desordem urbana; e Ásia, o novo rosto urbano do mundo - cada uma com sua lógica intrínseca e narrativa própria.
}

* (SONTAG, Susan. Op. cit.: 11).

* (SCHOLLHAMMER, Karl Erik. "Imagens na margem do mundo globalizado". In: Além do visível: o olhar da literatura. Rio de Janeiro: 7Letras, 2007: 189.) 
* (BENTES, Ivana. "Quando o árido vira fome". Disponível em: http://jbonline.terra. com.br/destaques/glauber/ glaub_arquivo41.html.)

* (OMAR, Arthur. Op. cit.: 1997: 24.)

* (SOUZA, Eneida Maria de. "Marioswald pós-moderno". In: CUNHA, Eneida Leal (org.). Leituras críticas sobre Silviano Santiago. Belo Horizonte: UFMG; São Paulo: Fundação Perseu Abramo, 2008: 23-50.)

* (PRADO, Marcos. Jardim Gramacho. Rio de Janeiro: Argumento, 2004: 120.) ou museu exótico, a ser resgatado pelo grande espetáculo".* A espetacularização da dor comove, mas talvez não mova.

Isso não acontece nem na Antropologia da face gloriosa nem nas recentes Zootopias, ambas reuniōes dos trabalhos de Omar, que singularizam, de um modo radical, o instantâneo de um rosto de modo que, a cada foto, o espectador tenha de retirar de si recursos perceptivos inusitados. "São faces sem retrato", explica o fotógrafo-poeta. São faces que barram a retórica da dor e da piedade para magnetizar o espectador, "cada face gloriosa deve ser um ato de fundação, um momento fundamental."*

No artigo, "Marioswald pós-moderno", Eneida Maria de Souza recupera uma trilha de imagens dionisíacas às quais o pensamento crítico de Silviano Santiago imprime força suplementar, ao fazer delas uma teoria "pagã do dispêndio, da alteridade e da falta como categorias formadoras do sujeito".* Trata-se das imagens da negra no carnaval que despertaram em Mário de Andrade "o sentimento religioso da vida" e das reapropriações dessa imagem feitas por Silviano em seus ensaios críticos e textos ficcionais, "imprimindolhe significados conforme o contexto" em que se encontram. Essas imagens concorreriam para uma transfiguração da dor, um deslocamento desse significante do sentimento de autopiedade para a explosiva erótica de uma felicidade extraída do apetite de vida, da grande fome de viver.

Quando assisti ao documentário Estamira, do diretor Marcos Prado, reconheci as referências a essas forças que explodem as imagens da pobreza por um desvio violento e que, ao invés de olhar para o outro e falar pelo outro, permitem que eu seja olhada e falada por esse outro. Como ainda não se utilizava de recursos realistas como o cheiro do lixão invadindo a sala do cinema, pude resistir ao abalo provocado pela força do que aquela mulher me dizia:

"[...] porque eu não estava precisando desse remédio. Quem sabe sou eu, quem sabe é o cliente. Fica se viciando, dopando, vadiando pra terra suja, maldita, excomungada, desgraçada, mais ainda. Quê que há? Manjado, desmascarado, desgraça... Os limites. Toda coisa tem limite. Esses remédios são da quadrilha da armação dopante pra cegar os homens pra querer Deus. Deus falsário, entendeu? Esses remédios são dopantes pra querer Deus falsário, entendeu? [...] Vocês não aprendem na escola, vocês copiam, vocês aprendem é com as ocorrências. Eu tenho neto com dois anos que já sabe disso. Tem dois anos que ainda não foi na escola copiar hipocrisias e mentiras charlatais."* 
Da mesma forma que Estamira me desloca de meus preconceitos de classe, a literatura de $A$ hora da estrela é capaz de tornar a dor inédita e cada vez mais cruel. Leio a hora extrema e gloriosa do atropelamento de Macabéa como um desses instantâneos da dor em que a luz explode a significação. O sem sentido da morte está inscrito nessas últimas respiraçôes, misturadas ao vômito de sangue. Não quero, recuso-me a sentir piedade neste momento cruel e glorioso da nordestina, em que ela alcança, sem o saber, o agudo âmago de seu desejo, tem a sua irônica, mas incomparável, hora de estrela. "A morte é um encontro consigo. Deitada, morta, era tão grande como um cavalo morto.”* Experimento o júbilo em acompanhar uma vida que se cumpre, momento seguido de um grito de vitória por eu-leitor ter sobrevivido a essa morte. É a essa euforia escandalosa à qual o leitor pode chegar ao término do romance: " $\mathrm{E}$ - agora só me resta acender um cigarro e ir para casa. Meu Deus, só agora me lembrei que a gente morre. Mas - mas eu também?!/ Não esquecer que por enquanto é tempo de morangos./ Sim."” A afirmação de vida da última palavra do romance, o Sim inequívoco e desapiedado, torna-se o osso do contrassenso batailleano, é o recurso que desmobiliza a retórica da dor: a crueldade da arte permite a confrontação com a minha crueldade.

E, se a piedade impede o reconhecimento de qualquer possibilidade de alguém ser feliz fora dos parâmetros de felicidade burguesa/capitalista e consola com um estado de culposa consciência quem busca diminuir a permanente fome de comida dos pobres, a piedade não é suficiente para estancar neles a fome de vi$\mathrm{da}$, a vontade de felicidade, a possibilidade de serem como Macabéa, certa "flor fresca". E talvez impedir-lhes - por manter o olhar piedoso que os acalenta e os afasta, por não conceder-lhes o direito à alegria gozosa, mantendo-os discursivamente na condição de pobres, incapacitados, excluídos, miseráveis, infelizes, necessitados (não admitir neles essa avidez) - essa fome potente e ameaçadora, do que é a grande vida que explode nas fotos de Omar, nas imagens da negra, no discurso paranoico-lúcido de Estamira e no destino de Macabéa. Mantê-los infelizes à distância, talvez seja essa a forma mais sutil e perversa de barrar sua entrada no clube. Talvez para a piedade culposa seja forçoso guardar os anjos do porão somente no lado da fome, da doença, da miséria, com seus doloridos rostos voltados para trás como se fossem ruínas; pois assim a tarefa 
se estende adiante e a longo prazo, a tarefa os mantém ali carentes e necessitados de ajuda.

À crueldade da arte cabe deixar que, livre das imposições racionalizantes, alguém em permanente jejum force a passagem para a dimensão da miséria e admita a potência guardada ali e, de um modo mais respeitoso para a própria força desse olhar inaugural, possa se ver livremente na face do Outro uma face singular, ameaçadora e nova: "E quando se presta atenção espontânea e virgem de imposições, quando se presta atenção a cara diz quase tudo".*

\section{Ana Chiara (Ana Cristina De Rezende Chiara)}

é doutora em Letras pela PUC-Rio e professora adjunta de Literatura Brasileira na Universidade do Estado do Rio de Janeiro (UERJ) desde 1995. Dedica-se à pesquisa nos seguintes temas: corpo, sexualidade, memória. Interessa-se, no momento, por imagens que apresentem a emergência da transitoriedade das formas ou de formas corporais inéditas e, sobretudo, as possibilidades de a linguagem da arte enunciar essas formas no conjunto das transformaçôes culturais contemporâneas. É autora dos livros Pedro Nava: um homem no limiar (EDUERJ, 2001) e Ensaios de Possessão (Irrespiráveis) (Caetés, 2006), e do inédito Teoria em Transe. Participa do GT ANPOLL de Literatura Comparada e Coordena o GPESq Corpo \& Experiência (http://gpcorpoexperiencia.blogspot.com/).

\section{Resumo}

Palavras-chave: Êxtase; face gloriosa; A hora da estrela; Êxodos; Estamira.
Keywords: Ecstasy; glorious face; $A$ hora da estrela; Êxodus; Estamira.

Mots-clés: Extase; face glorieuse; A hora da estrela; Exodes; Estamira.

Este artigo discute imagens da pobreza que figuram tanto na literatura quanto em outras linguagens, em perspectiva comparatista e desconstrutora do olhar preconceituoso e/ou piedoso. $\mathrm{O}$ foco da discussão é o conceito de êxtase (Bataille) e de face gloriosa (Arthur Omar). Os objetos são: A hora da estrela (Clarice Lispector), as fotos do projeto $\hat{E x o d o s ~(S e b a s t i a ̄ o ~ S a l g a d o) ~ e ~ o ~ d o c u m e n t a ́ r i o ~}$ Estamira (Marcos Prado).

\section{Abstract}

This article discusses images of poverty which appear in literature as well as in other languages, in a comparatist and deconstructive perspective of prejudiced and/or merciful views.

\section{Resumé}

Dans cet article on étudie des images de la pauvreté figurant dans la littérature autant que dans d'autres langages, sous un rapport comparatif et déconstructeur du regard du préjugé 
The focus of the discussion is ou de la pitié. On s'appuie sur the concept of ecstasy (Batail- les concepts d'extase (Bataille) et le) and of glorious face (Arthur de face glorieuse (Arthur Omar). Omar). The objects are: $A$ ho- Les objets sont $A$ hora da estrela ra da estrela (Clarice Lispector), I L'Heure de l'étoile (Clarice Listhe photos of Migrations project pector), des photos du projet (Sebastiāo Salgado) and the do- Exodes (Sebastião Salgado) et le cumentary film Estamira (Mar- documentaire Estamira (Marcos Prado). cos Prado). 